\title{
ICEM2010-40121
}

\section{DEVELOPMENT OF CHARACTERIZATION TECHNOLOGY FOR FAULT ZONE HYDROLOGY}

\author{
Kenzi Karasaki \\ Lawrence Berkeley National \\ Laboratory \\ Berkeley, CA, USA \\ Junichi Goto \\ Nuclear Waste Management \\ Organization of Japan \\ Mita, Tokyo, Japan \\ Keiichi Ueta \\ Central Research Institute for \\ Electric Power Industry \\ Abiko, Chiba, Japan
}

\author{
Celia Tiemi Onishi \\ US Geological Survey \\ Menlo Park, CA, USA \\ Hiroyuki Tsuchi \\ Nuclear Waste Management \\ Organization of Japan \\ Mita, Tokyo, Japan \\ Kenzo Kiho \\ Central Research Institute for \\ Electric Power Industry \\ Abiko, Chiba, Japan
}

\author{
Erika Gasperikova \\ Lawrence Berkeley National \\ Laboratory \\ Berkeley, CA, USA \\ Tadashi Miwa \\ Nuclear Waste Management \\ Organization of Japan \\ Mita, Tokyo, Japan \\ Kimio Miyakawa \\ Central Research Institute for \\ Electric Power Industry \\ Abiko, Chiba, Japan
}

\begin{abstract}
Several deep trenches were cut, and a number of geophysical surveys were conducted across the Wildcat Fault in the hills east of Berkeley, California. The Wildcat Fault is believed to be a strike-slip fault and a member of the Hayward Fault System, with over $10 \mathrm{~km}$ of displacement. So far, three boreholes of $\sim 150 \mathrm{~m}$ deep have been core-drilled and borehole geophysical logs were conducted. The rocks are extensively sheared and fractured; gouges were observed at several depths and a thick cataclasitic zone was also observed. While confirming some earlier, published conclusions from shallow observations about Wildcat, some unexpected findings were encountered. Preliminary analysis indicates that Wildcat near the field site consists of multiple faults. The hydraulic test data suggest the dual properties of the hydrologic structure of the fault zone. A fourth borehole is planned to penetrate the main fault believed to lie in-between the holes. The main philosophy behind our approach for the hydrologic characterization of such a complex fractured system is to let the system take its own average and monitor a long term behavior instead of collecting a multitude of data at small length and time scales, or at a discrete fracture scale and to "up-scale," which is extremely tenuous.
\end{abstract}

\section{INTRODUCTION}

The Nuclear Waste Management Organization of Japan (NUMO) and the Ernest Orlando Lawrence Berkeley National Laboratory (LBNL), one of the U.S. Department of Energy's (DOE) National Laboratories, have been collaborating to

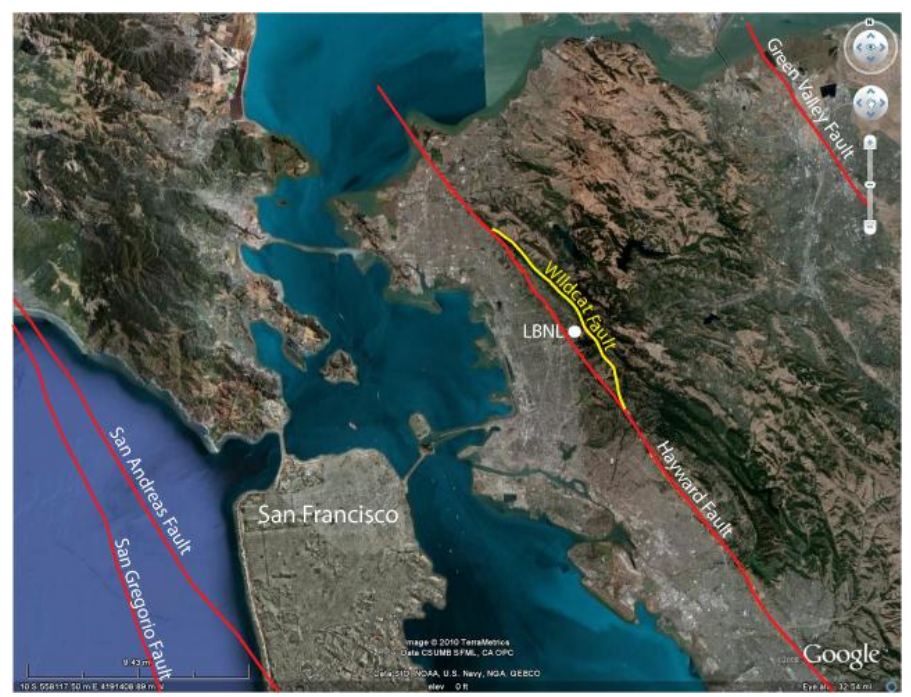

Figure 1 Location of LBNL and the Wildcat Fault relative to the major faults in San Francisco Bay Area. 
develop a methodology for characterizing the hydrology of fault zones, recognizing that the efficient and reliable characterization of faults is crucial to the safe geologic isolation of nuclear wastes.

Given the geologic environment of the Japanese Islands - they are likely to exist almost everywhere-faults need to be assessed both at the preliminary and the detailed investigation stage (the length scale of the faults of interest could range from several kilometers in the former down to several hundred meters in the latter).

Efforts in the past, though, have rarely addressed the development of a systematized hydrologic characterization technology specifically tailored for fault zones. Instead, it has been necessary to use overly conservative values for the hydrologic parameters of fault zones in the design and performance assessment of a repository. Thus, development of a more efficient and reliable fault-zone characterization technology is acutely needed. The geologic properties of faults and the relationships among their geometry, type, fault parameters, and internal structures have been investigated in the past. However, the relationship between the geologic and hydrologic properties of faults is not yet studied sufficiently. Karasaki et al. [1] concluded that there is very little available in the literature that relates the geologic structure of faults to hydrology, that it still may be feasible to classify faults based on geologic attributes to predict their hydrologic characteristics, and that it is critical to establish a field investigation technology for fault zone hydrology.

The Wildcat Fault (Figure 1), which is a predominantly strike-slip fault and a member of the Hayward Fault system, was chosen to be the target fault of the field study. Wildcat runs through the LBNL property, within and around which surfacebased investigations have been conducted. A total of five trenches have been excavated. Surface geophysical investigations were conducted using electrical resistivity survey and seismic reflection profiling along four lines on the north, in the middle and to the south of the LBNL site. In addition, three $150 \mathrm{~m}$ deep boreholes were drilled.

The present paper presents an overview of this ongoing project, the results of which have so far been intriguing, and in some ways contradictory to past, published work regarding this site.

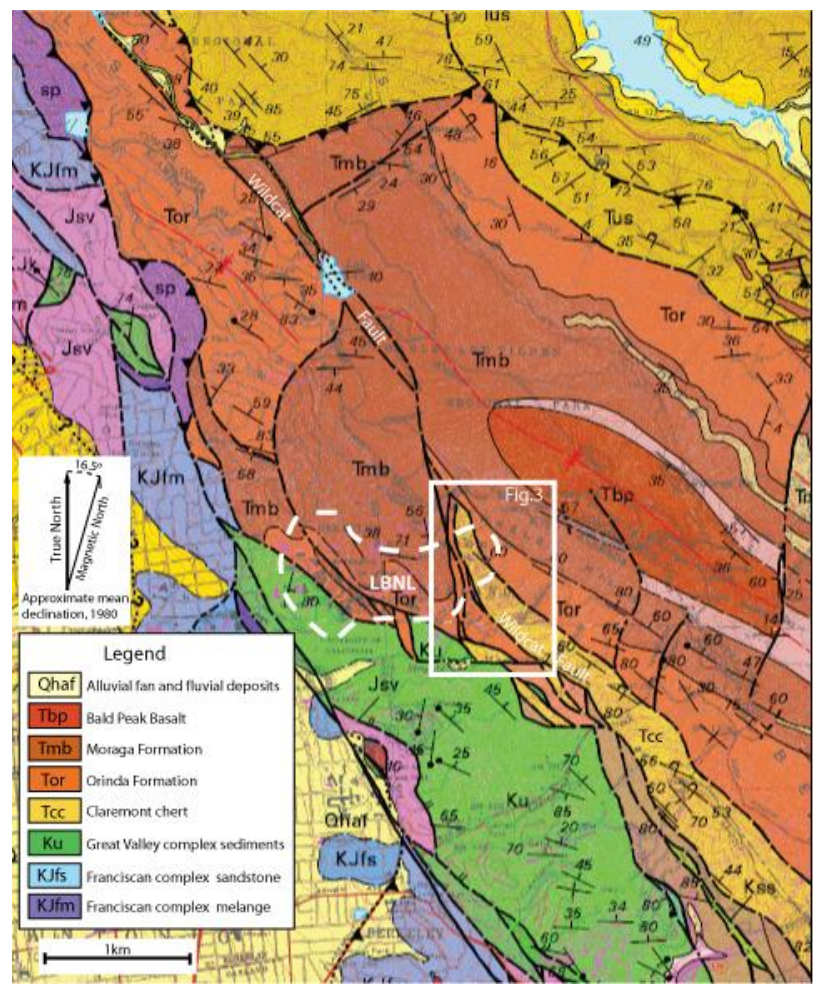

Figure 2 Geologic map of the area around the LBNL site, modified after Graymer[6]. The location of LBNL and the area shown in Figure 3 are indicated by broken and solid white lines, respectively.

Table 1 Regional Stratigraphy of San Francisco Bay Area (Compiled from [2], [3] and [6])

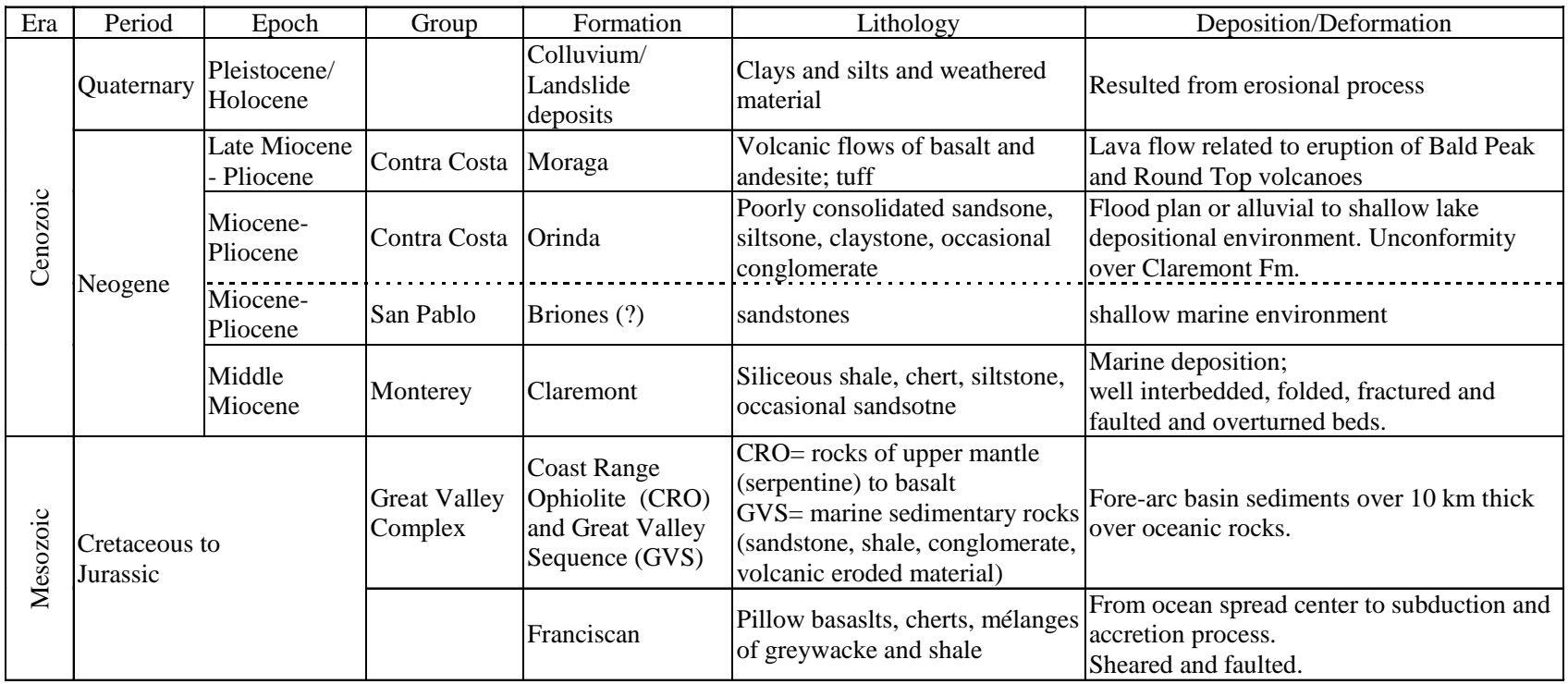




\section{AREA GEOLOGY AND WILDCAT FAULT}

The geologic setting of the San Francisco Bay Area is intertwined with some of the most complex and active geology in the world. California geology as a whole is a result of plate subduction, active volcanoes, and faults along plate boundaries, with bedrock age ranging from Jurassic to Pliocene (Table 1). The oldest rock in the Bay Area region is from the Jurassic to Cretaceous age (200-65 Ma) Franciscan assemblage, which was originally deposited in a deep marine environment and trench deposits. It was subsequently accreted during a plate subduction along the coast of Northern California. Over more than 100 million years of subduction, accretion brought together many types of Mesozoic rock that we now see in the Bay Area. Extensive tectonic activity uplifted and folded the Franciscan mélanges, which consisted of exotic blocks of basalt, chert, and limestone embedded in a matrix of sheared greywacke and shales. The Wildcat fault is considered to be a secondary splay fault associated with the Hayward fault. It cuts late Cenozoic strata, striking subparallel to the Hayward Fault.
The fault, which runs about one and one-half kilometers east of the Hayward Fault, has been considered as part of the San Andreas Fault system but no clear evidence of activity in the Quaternary has been identified [2]. Wildcat passes along the eastern margin of LBNL and runs from Oakland to Richmond. Regionally, the fault is difficult to map throughout its length and appears to be discontinuous, although it clearly truncates and offsets strata at many locations. At regional scale, the fault shows right-lateral strike-slip movement [3], and local reverse movement has also been observed and described [4]. According to Bishop [5], the Wildcat Fault eventually joins the Hayward Fault in the north near the city of San Pablo and in the south in Oakland [6]. From the geological map (Figure 2) and our aerial photo analysis, the fault appears to be straight and single in the northern part, while splitting and complicated in the southern part where LBNL is located. Based on our preliminary fault classification scheme, the northern part suggests a potentially well-defined hydrological barrier, while the interpretation of the southern part yields multiple hydrologic conceptual models.

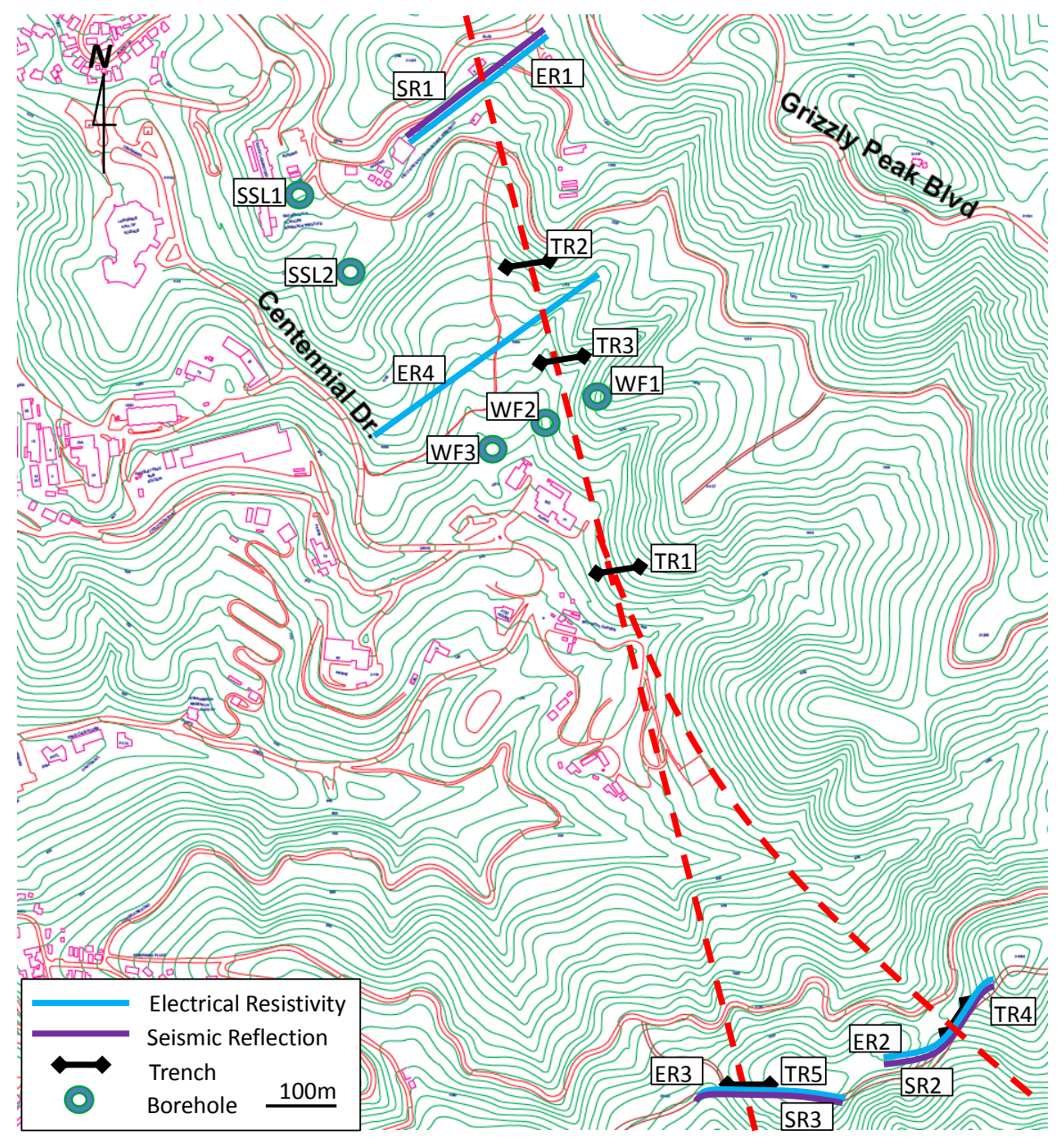

Figure 3 Map showing the location of surface geophysical survey lines, trenches, boreholes and inferred trace of the Wildcat Fault (red broken lines). 


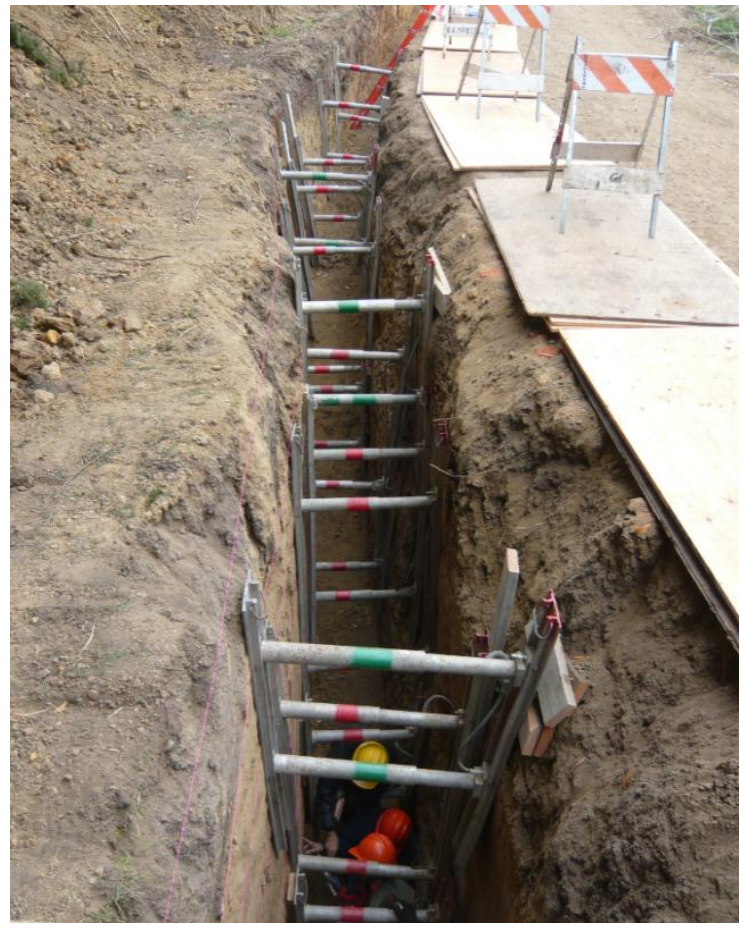

Figure 4 Geologists mapping the wall of the TR-4 trench on the Ridge Road south of LBNL excavated as deep as $4.5 \mathrm{~m}$ and $60 \mathrm{~m}$ long.

\section{TRENCHING AND GEOPHYSICAL SURVEYS}

A total of five trenches have been excavated, crosscutting the fault, to investigate the deformation structure of the fault in the bedrock (Figure 3). The locations were chosen based on the literature and evidence from road/building construction, as well as newly conducted geological surveys. The TR-4 trench was $60 \mathrm{~m}$ long, dug as deep as $4.5 \mathrm{~m}$, with a width of $1 \mathrm{~m}$ (Figure 4). At least one to (as many as) several faults were observed in all five trenches, although it is yet to be determined whether any of the trenches have intersected the "main" fault. Trench studies are effective when the location of a fault is known and the thickness of the alluvium above the bedrock is not very thick; however, because the observation is near-surface, the properties of the fault may be affected by stress release and weathering. Thus, care must be taken when inferring properties at depth.

Four electrical resistivity surveys and three reflection seismic surveys were conducted at four separate locations across the fault trace. Figure 3 shows the locations of these geophysical survey lines, which were chosen to cross the fault perpendicularly while maintaining a straight line-as much as possible in the extremely hilly terrain. Choosing the seismic lines were particularly challenging, because they had to be accessible by the vehicle mounted with a seismic source.

Although it was possible to infer the existence of multiple discontinuities from the results of seismic reflection analysis and resistivity profiling, the geophysical results were largely inconclusive in locating the fault. This is because the geology of the Berkeley Hills is very complex, as discussed above. The Claremont chert formation is extensively folded, fractured and faulted, with no clear reflective horizons. (Because of the steep terrain, there are many landslides.) However, the most recent electrical resistivity survey, using the dipole-dipole technique along the ER4 line shown in Figure 3, revealed two discontinuities rather clearly. Figure 5 shows the inverted resistivity map. As can be seen from the figure, discontinuities can be seen at $\sim 140 \mathrm{~m}$ and $240 \mathrm{~m}$ from the east end of the profile. It is assumed that the discontinuity at $140 \mathrm{~m}$ is the Wildcat Fault. The other discontinuity could be the East Canyon Fault, whose existence has been disputed in the past.

\section{BOREHOLE DRILLING AND LOGGING}

Three boreholes have been drilled so far, each to an approximate depth of $150 \mathrm{~m}$ by mud-rotary with full coring. Figure 3 shows the location of these boreholes, WF-1, WF-2 and WF-3. Also shown are SSL-1 and SSL-2, which were installed about 30 years ago to mitigate landslides, and were recently equipped with pressure and flow sensors.

The lithology observed in WF-1 was entirely of the Claremont formation, showing chert interbedded with shale and occasional massive sandstone having no apparent sedimentary texture. The location of WF-2 was chosen because it was previously mapped as the Orinda/San Pablo formation, so that WF-2 would be on the western side of the Wildcat fault. However, our drilling revealed that the Orinda/San Pablo formation extends only to a depth of $18 \mathrm{~m}$, where the rock becomes the Claremont formation to the bottom hole depth of

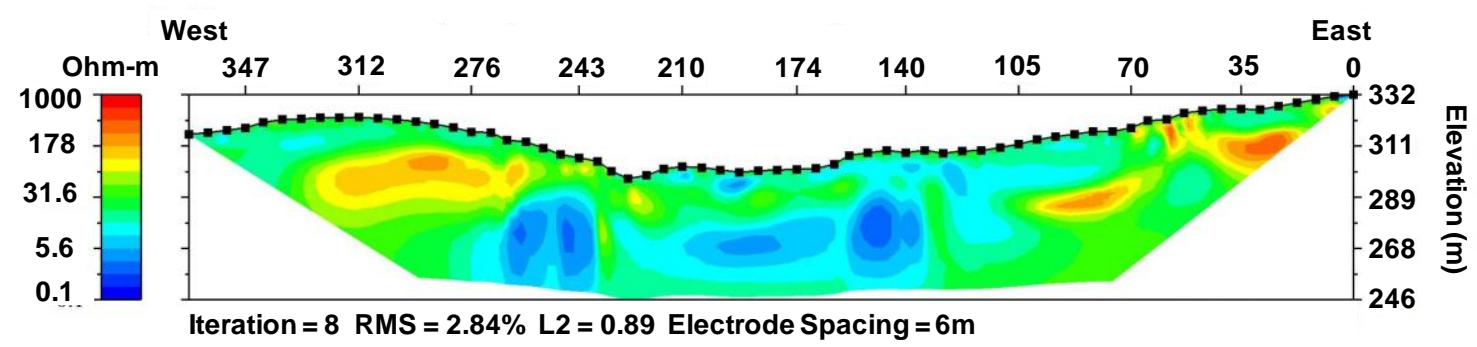

Figure 5 Inversion result of the resistivity survey along ER4 shown in Figure 3 Discontinuities are suspected at near $140 \mathrm{~m}$ and $240 \mathrm{~m}$ from the East. 


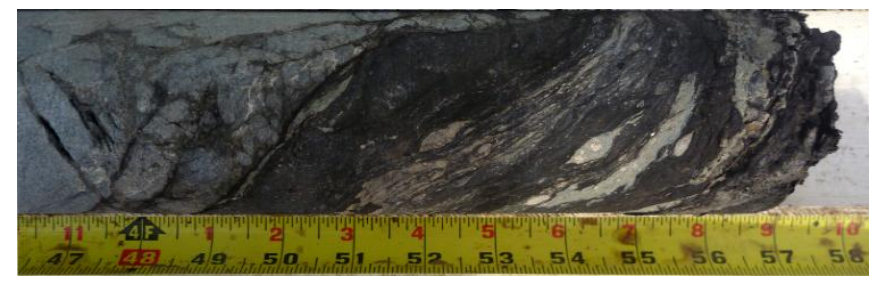

Figure 6 The core of foliated cataclasite at 92m depth in WF-2 consisting of highly sheared, anastomosed, stretched fragments of light yellow soft to hard siltstone and light gray sandstone embedded in a matrix of sheared black shale.

$150 \mathrm{~m}$. This prompted us to drill the third hole, WF-3, at $\sim 100$ $\mathrm{m}$ west of WF-2, hoping to bracket the extent of the Claremont formation. In WF-3, the Orinda silt formation was encountered to a depth of $75 \mathrm{~m}$, where it turned into San Pablo sandstone. At $98 \mathrm{~m}$ depth, the Claremont formation emerged again. The Orinda formation appeared again at $147 \mathrm{~m}$ to $154 \mathrm{~m}$, where the drilling was terminated. At selected intervals in each borehole, core samples were taken aside and vacuum preserved for helium isotope analysis, the results of which are not yet available.

Several shear zones and fault gouges were observed in all three boreholes, in addition to several hundred fractures. Figure 6 shows one of the shear zones observed in the core at $92 \mathrm{~m}$ from WF-2: a foliated cataclasite consisting of highly sheared, anastomosed, stretched fragments of siltstone and sandstone embedded in a matrix of sheared black shale. Whether any one of the zones is the main Wildcat fault or, if not, how they are related to the Wildcat Fault, is not clear. There still is a distinct possibility that the main fault lies between WF-1 and WF-2. At this writing, a fourth borehole, WF-4, is being considered. One plan is to drill in an inclined fashion from the west to the east, parallel to the line that connects WF-2 and WF-1 with some offset either to the north or south, which would encounter the main fault plane at an angle, if it indeed exists.

Borehole geophysical logs were conducted in all three boreholes including caliper, gamma, resistivity, acoustic televiewer, and sonic log. In addition, flowing fluid conductivity logs (FFEC) were conducted in each hole. FFEC logs can pinpoint inflow zones caused by the electric conductivity contrast artificially created between the formation fluid and that of the borehole under a pumping condition [7]. Figure 6 shows the FFEC results from WF-2 plotted against the tadpole and frequency plot of discontinuities, which include fractures and beddings. As can be seen from the figure, only one inflow point at $136 \mathrm{~m}$ was detected by the FFEC log, whereas 309 fractures and 152 beddings were counted by the televiewer log. This result shows that the fracture density is not a good indicator for flow. In fact, the inflow point is at a depth where fracture density is at its lowest. Similar results were obtained in the other two boreholes.

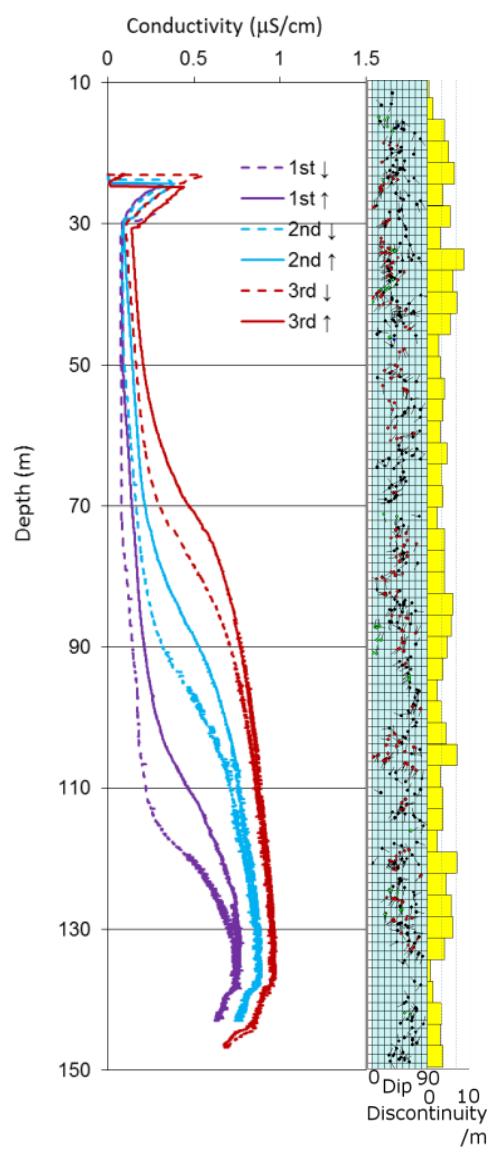

Figure 7 FFEC log results plotted against the tadpole plot of discontinuity and discontinuity counts based on televiewer analysis in WF-2.

\section{HYDRAULIC TESTS AND MONITORING}

Slug tests, injection tests, and pumping tests were conducted in the boreholes to estimate the transmissivity of each borehole. Although the rock is highly fractured and the

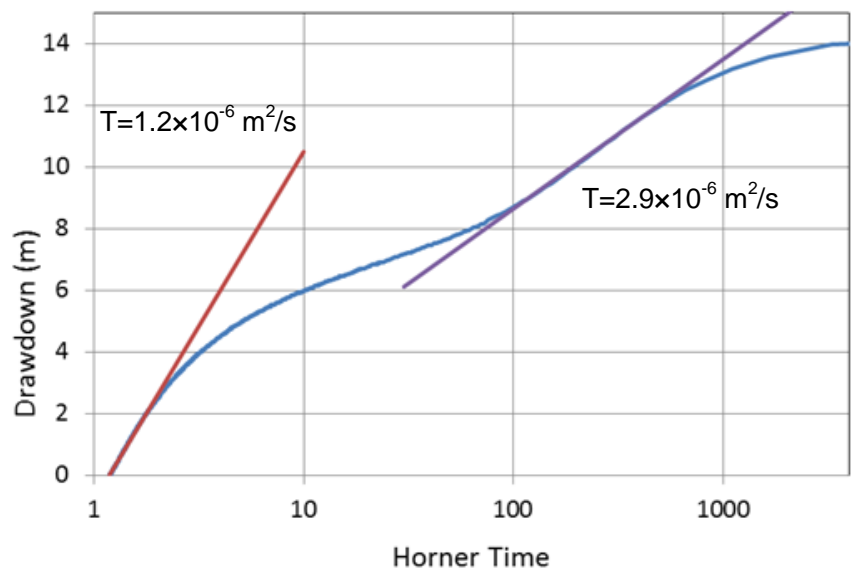

Figure 8 Horner plot of the recovery data of a pumping test in WF-2 with a packer at $76 \mathrm{~m}$. Note the double humps in the recovery data that may be indicative of a fault. 
flow is presumably fracture controlled, no attempts were made to measure the permeability of discrete fractures. This is because: (1) the scale of interest is over $100 \mathrm{~m}$, (2) time and resources are limited, and most importantly, (3) we do not believe that "scaling up" of small-scale measurements to predict large-scale properties will work in this geologic environment.

Interestingly, injection tests almost always yielded much smaller permeabilities compared to those from pumping tests conducted in the same interval, which is counter intuitive. We only surmise that flow paths in fractures near the borehole may get constricted by some wedge-like effect at higher injection pressure.

Figure 8 shows the Horner plot for the recovery data after WF-2 was pumped for $\sim 10$ hours below the packer at $7 \mathrm{~m}$ depth, i.e., water was pumped from the interval between $76 \mathrm{~m}$ and $150 \mathrm{~m}$. As can be seen from the figure, there are twol inflection points, which can be interpreted in multiple ways. The most likely interpretation is that the transmissivity of the rock near the borehole, roughly $3 \times 10^{-6} \mathrm{~m}^{2} / \mathrm{s}$, precedes a higher transmissivity zone beyond it, possibly the fault damage zone, and finally seeing the effect of a no-flow boundary caused by the core of the fault. This interpretation is based on the final asymptotic straight line having a slope roughly twice that of the first line, as shown in Figure 8.

The hydraulic tests conducted in WF-1 and SSL-1 also indicate the possibility of the effects of a fault or faults (not shown). Extensive hydraulic tests are planned in the yet-to-bedrilled fourth borehole using the existing boreholes as observation holes. At the end of the pumping tests, water

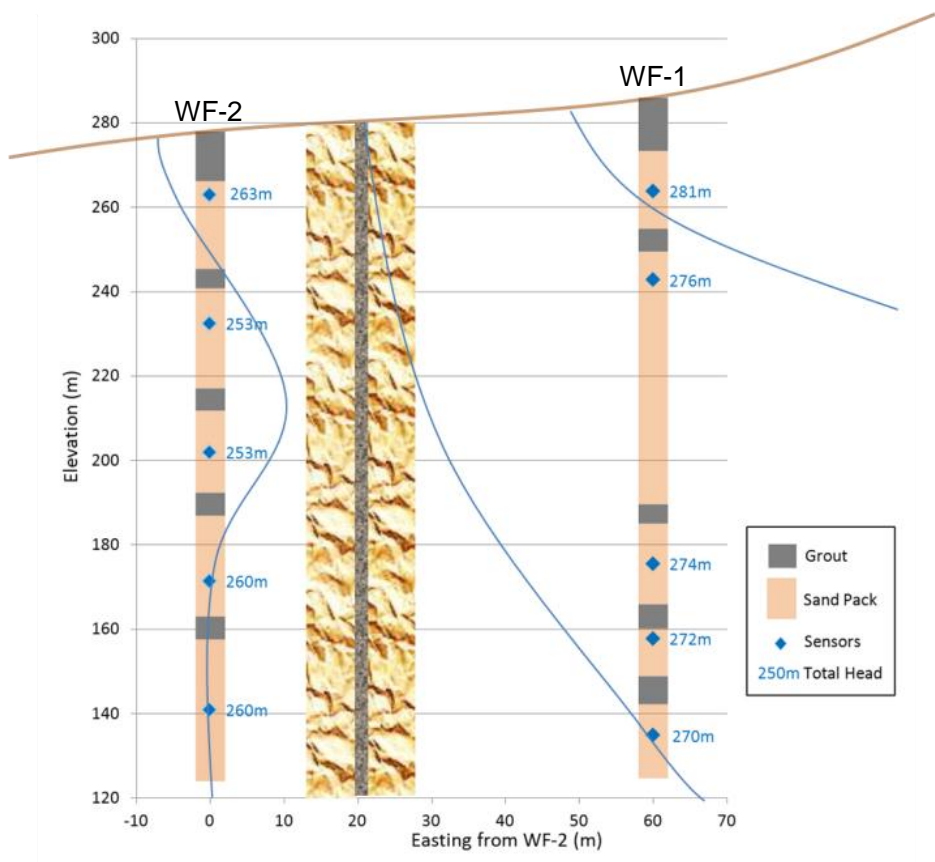

Figure 9 Plot showing the location of the sensors and completion intervals. Also shown are the hydraulic head contours. In the middle is the suspected Wildcat Fault. samples were taken for geochemical analysis, whose results are not yet available at this writing.

\section{BOREHOLE COMPLETION AND MONITORING}

WF-1 and WF-2 boreholes have been completed with alternating zones of sand pack and grout. A pressure and temperature sensor has been embedded in each sand-packed zone. This is a low cost alternative to using multiple packer systems.

Figure 9 shows the monitoring intervals and the location of sensors in WF-1 and WF-2. Also shown are the total head values and the contors. The heads in WF-1 descease with depth, indicating a downward flow, whereas in WF-2, the head is the lowest in the mid depth of the hole. These non-monotonic heads indicate the complex nature of the hydrology near the fault. WF-3 is not yet completed at this writing.

\section{SUMMARY AND FUTURE PLANS}

The Wildcat Fault is a known mapped fault. However, it turns out that it is very challenging to pinpoint the location of the main fault (deformation zone). Multiple shear zones were observed in trenches and boreholes. Shallow geophysical surveys in such a complex geology have yielded inconclusive results. The results of hydraulic tests appear to show the dual properties of the fault: high permeability along the fault in the damage zone and low permeability across it. A fourth, inclined borehole, WF-4 is planned to be drilled. Interference tests from WF-4 to other WF holes should reveal the hydrologic structure of the fault, as well as the geochemical analysis of the waters from these boreholes.

\section{ACKNOWLEDGMENTS}

The authors would like to thank Preston Jordan of LBNL for useful suggestions and discussions as well as the anonymous reviewers of this manuscript. This work was performed under U.S. DOE Contract No. DE-AC02$05 \mathrm{CH} 11231$.

\section{REFERENCES}

[1] Karasaki, K., Onishi, C.T., and Wu, Y.S., 2008, "Development of Hydrologic Characterization Technology of Fault Zones", Lawrence Berkeley National Laboratory Report, LBNL-1635E.

[2] LBNL and Parsons, 2000, "RCRA Facility Investigation Report for the Lawrence Berkeley National Laboratory Environmental Restoration Program. A Joint Effort of Environment, Health and Safety Division and Earth Sciences Division Lawrence Berkeley National Laboratory University of California Berkeley and Parsons Engineering Science, Inc".

[3] Curtis, G.H., 1989, "Late Cenozoic volcanic rocks of the central Coast Range, in Wahrhaftig, C., and Sloan, D., Geology of San Francisco and vicinity, Field trip guidebook T 105: Washington, D.C., American Geophysical Union, pp. 33-35.

[4] Jones, D.L. and Curtis, G., 1991, "Guide to the geology of the Berkeley Hills, Central Coast Ranges, California" in Geologic Excursions in Northern California: San Francisco to 
the Sierra Nevada, California Departmanent of Conservation, Division of Mines and Geology. Special Publication 109, pp 63-73.

[5] Bishop , C.C., Knox R.D., Chapman R.H., Rodgers D.A., and Chase G.B., 1973, "Geological and Geophysical Investigations for Tri Cities Seismic Safety and Environmental Resources Study". California Division of Mines and Geology, $19,44 \mathrm{p}$.

[6] Graymer, R.W., 2000, "Geologic map and map database of the Oakland metropolitan area, Alameda, Contra Costa and San Francisco Counties, California". USGS Miscellaneous Field Studies MF3242g. Version 1.0, 2000.

[7] Doughty , C., Tsang, C.F., Hatanaka, K., Yabuuchi, S., and Kurikami, H., 2008, "Application of direct - fitting, mass integral, and multirate methods to analysis of flowing fluid electric conductivity logs from Horonobe, Japan", Water Resour. Res., 44, W08403, doi:10.1029/2007WR006441. 
